\title{
Assessment of the annual performance of solar collectors by means of the utilizability method
}

\author{
Merima Zlateva ${ }^{1, *}$ \\ ${ }^{1}$ Technical University Sofia, Department of Heating and Refrigeration Engineering, 1000 Sofia, \\ Bulgaria
}

\begin{abstract}
This report presents some results from a comparative analysis of the long-term efficiency of flat-plate and evacuated tube solar collectors under different operating conditions. The analysis involves calculation of the daily utilizibility factor, which is defined as the fraction of total monthly solar radiation over an inclined surface that exceeds the critical value. The monthly values of the critical radiation and the daily utilizability factor for the solar collectors are determined under different climatic conditions and different temperatures of the heat transfer fluid. The obtained results are used to compare the annual performance of the solar collectors.
\end{abstract}

\section{Theoretical considerations}

\subsection{Instantaneous efficiency of solar collectors}

The characteristics of solar thermal collectors have significant impact on the utilization of available solar energy. Their main impact is on the efficiency of the process of capturing and converting the solar radiation, on which the total heat losses of the collectors depend.

The efficiency of solar collectors is determined as:

$$
\eta_{S C}=F_{R} \cdot(\tau \cdot \alpha)_{n}-F_{R} \cdot U_{L} \cdot \frac{\left(\vartheta_{a v}-\vartheta_{e}\right)}{G}
$$

where $F_{R}$ is the heat removal coefficient of the solar collector, taking into account the variable intensity of heat transfer between the absorber and the heat transfer fluid; rays $0^{\circ}$;

$(\tau \cdot \alpha)_{n}$ - the transmittance - absorptance product at an angle of incidence of the sun's

$U_{L}$ - overall heat loss coefficient of the collector, $\mathrm{W} / \mathrm{m}^{2} \mathrm{~K}$;

$\vartheta_{a v}$ - average temperature of the heat transfer fluid in the solar collector, ${ }^{\circ} \mathrm{C}$;

$\vartheta_{e}$ - outdoor air temperature, ${ }^{\circ} \mathrm{C}$;

$G$ - intensity of solar radiation, $\mathrm{W} / \mathrm{m}^{2}$.

\footnotetext{
*Corresponding author: mzlat@tu-sofia.bg
} 
In equation (1) the collector efficiency is defined as a linear function of the parameter $\left[\left(\vartheta_{a v}-\vartheta_{e}\right) / G\right]$. The coefficient $\eta_{0}=F_{R} \cdot(\tau \cdot \alpha)$, often referred to as optical efficiency, provides information about the rate of transmittance of solar radiation through the transparent cover and its absorption by the absorber in the absence of heat losses. The coefficient $F_{R} \cdot U_{L}$ is a criterion for the quality of the thermal insulation and takes into account the behaviour of the collector under variable operating conditions.

For each collector, characterized by the heat loss coefficient $F_{R} \cdot U_{L}$ and the optical efficiency $F_{R} \cdot(\tau \cdot \alpha)$, under specific operating conditions depending on the temperatures $\vartheta_{a v}$ and $\vartheta_{e}$, there is a certain critical value of solar radiation, at which the absorbed heat is equal to the heat losses to the surrounding.

$$
G_{T, c}=\frac{F_{R} U_{L} \cdot\left(\vartheta_{a v}-\vartheta_{e}\right)}{F_{R} \cdot(\tau \cdot \alpha)}
$$

When $\left(G_{T}=G_{T, c}\right)$ the radiation absorbed by the collector is used entirely to compensate for its heat losses. The utilization of the available solar radiation is possible when $G_{T}>G_{T, c}$. This requirement is often used as a criterion for managing the periods when the circulation pump in the solar systems should work.

\subsection{Daily utilizability method}

The concept of defining and applying the criterion "utilizability factor", based on calculations with statistical data on the distribution of solar radiation in different time periods (hour, month or year) was developed by Hottel and Whillier, Lui and Jordan (1963) [1], Collares-Pereira and Rabl (1979) [2], Evans et al. (1982) [3]. The specific features of the methodologies developed by them are presented in [4], [5], [6] and others. The utilizability method can be applied for both thermal and photovoltaic systems [7].

At certain integral values of the critical $I_{T, c}$ and the total solar radiation $I_{T}$ on a tilted on angle $\beta$ surface, the hourly utilizability factor $\phi_{h, i}$ is defined by (3) and has values in the range $\phi_{h}=[0 \div 1]$ :

$$
\phi_{h}=\frac{\left(I_{T}-I_{T, c}\right)^{+}}{I_{T}}
$$

where $\left(I_{T}-I_{T, c}\right)^{+}$denotes the positive values of the difference $\left(I_{T . i}-I_{T, c . i}\right)$. The ratio $I_{T, c} / I_{T}=X_{c}$ is defined as dimensionless critical radiation.

The daily utilizability factor $\bar{\phi}$ is defined as the ratio of the monthly total solar radiation on an inclined surface $\sum_{N} \sum_{M}\left(I_{T}\right)$ exceeding a certain critical value $I_{T c}$ and its total monthly values $\left(N \cdot \bar{H}_{T}\right)$. The method for its application was developed by Klein [8]:

$$
\bar{\phi}=\frac{\sum_{N} \sum_{M}\left(I_{T}-I_{T c}\right)^{+}}{N \cdot \bar{H}_{T}}
$$


where $N$ is the number of days in the month; $M$ - number of hours in one day of the month; $I_{T c}$ - critical radiation determined by the optical efficiency $F_{R} \cdot(\tau \cdot \alpha)$, the heat loss coefficient of the solar collector $F_{R} U_{L}$ and on the average monthly outdoor temperature.

By using $\bar{\phi}$ it is possible to predict the monthly amount of energy utilized by the solar collectors as:

$$
Q_{m}=N \cdot \bar{H}_{T} \cdot \bar{\phi}=N \cdot \bar{H} \cdot \bar{R} \cdot \bar{\phi}
$$

where $\bar{R}=\bar{H}_{T} / \bar{H}$ is the ratio of the radiation on an inclined surface to that on a horizontal surface.

Klein also proves that the daily utilizability factor $\bar{\phi}$ can be represented as an exponential function of two variables - the geometric factor $\bar{R} / R_{n}$ and the dimensionless critical radiation $\bar{X}_{C}$, with a parameter the index of the monthly average clearness index $\bar{K}_{T}$. Its analytical form is shown in equation (6), in which the constants a, b and c have the following values:

$$
\begin{gathered}
a=2,943-9,217 \cdot \bar{K}_{T}+4,031 \cdot \bar{K}_{T}^{2} \\
b=-4,345+8,853 \cdot \bar{K}_{T}-3,602 \cdot \bar{K}_{T}^{2} \\
c=-0,170-0,306 \cdot \bar{K}_{T}+2,936 \cdot \bar{K}_{T}^{2} \\
\bar{\phi}=\exp \left\{\left[a+b \cdot\left(\frac{R_{n}}{\bar{R}}\right)\right] \cdot\left[\bar{X}_{c}+c \cdot \bar{X}_{c}^{2}\right]\right\}
\end{gathered}
$$

In (6) $R_{n}$ is the ratio of the radiation on an inclined and on horizontal surface in the solar noon for the average day of the month, and $\bar{R}$ is determined by the next equation:

$$
\bar{R}=\frac{\bar{H}_{T}}{\bar{H}}=\left(1-\frac{\bar{H}_{d}}{\bar{H}}\right) \cdot \bar{R}_{b}+\frac{\bar{H}_{d}}{\bar{H}} \cdot\left(\frac{1+\cos \beta}{2}\right)+\rho_{g}\left(\frac{1-\cos \beta}{2}\right)
$$

When adopting an isotropic model and using the available equations to determine the hourly from the monthly values of the total $r_{t}$ and diffuse $r_{d}$ solar radiation, $R_{n}$ can be calculated via (8). There $r_{t}=I / H$ and $r_{d}=I_{d} / H_{d}$ are calculated for the solar noon, and $R_{n}$ - for a day in which the total radiation is equal to the average monthly value ( $H=\bar{H}$ ). The average monthly critical radiation is determined for the same day, but as a ratio of the critical radiation to the radiation at the solar noon:

$$
\begin{aligned}
& R_{n}=\left(\frac{I_{T}}{I}\right)_{n}=\left(1-\frac{r_{d, n} \cdot H_{d}}{r_{t, n} \cdot H}\right) \cdot R_{b, n}+ \\
& +\left(\frac{r_{d, n} \cdot H_{d}}{r_{t, n} \cdot H}\right) \cdot\left(\frac{1+\cos \beta}{2}\right)+\rho_{g} \cdot\left(\frac{1-\cos \beta}{2}\right)
\end{aligned}
$$


The critical radiation is calculated as:

$$
\bar{X}_{C}=\frac{I_{T c}}{r_{t, n} \cdot R_{n} \cdot \bar{H}}
$$

\section{Comparative analysis of the efficiency of flat-plate and evacuated tube solar collectors}

Flat-plate and evacuated tube solar collectors, utilizing both direct and diffuse solar radiation, are suitable for the climatic conditions of Bulgaria. The comparative analysis of their efficiency is made for year-round operation using data for the average outdoor air temperature, the average monthly solar radiation and sky clearness index for the cities of Varna, Plovdiv and Sofia, which are located in climatic zones 1, 6 and 7. It is assumed that the climatic conditions of these zones are representative for most regions in Bulgaria Black Sea, Central, Southern and Western. The compared solar collectors have technical parameters typical for their current level of development:

Flat plate solar collector $(\mathrm{FP}): F_{R} \cdot(\tau \cdot \alpha)=0,81, F_{R} \cdot U_{L}=3,65 \mathrm{~m}^{2} \cdot \mathrm{K} / \mathrm{W}$;

Evacuated tube collector (ET): $F_{R} \cdot(\tau \cdot \alpha)=0,6, F_{R} \cdot U_{L}=1,059 \mathrm{~m}^{2} \cdot \mathrm{K} / \mathrm{W}$;

The comparative evaluation of the monthly efficiency of the two types of collectors is shown in Fig. 1. The values are calculated using the average monthly outdoor temperature $\vartheta_{e}$ and solar radiation $G$ at temperatures of the heat transfer fluid $\vartheta_{a v}=60{ }^{\circ} \mathrm{C}$ and $\vartheta_{a v}=90{ }^{\circ} \mathrm{C}$. The figure shows that throughout the year the efficiency of the flat-plate collector is higher and varies in the range $\eta_{F P}=[73,9 \div 79,9]$ at temperature $\vartheta_{a v}=90{ }^{\circ} \mathrm{C}$ and $\eta_{F P}=[76,4 \div 80,4]$ at coolant temperature $\vartheta_{a v}=60{ }^{\circ} \mathrm{C}$. For the evacuated tube collector the range of variation is smaller, as the respective values are significantly lower $-\eta_{V P}=[57,9 \div 59,7]$ at $\vartheta_{a v}=90^{\circ} \mathrm{C}$ and $\eta_{V P}=[58,7 \div 59,8]$ at $\vartheta_{a v}=90{ }^{\circ} \mathrm{C}$.

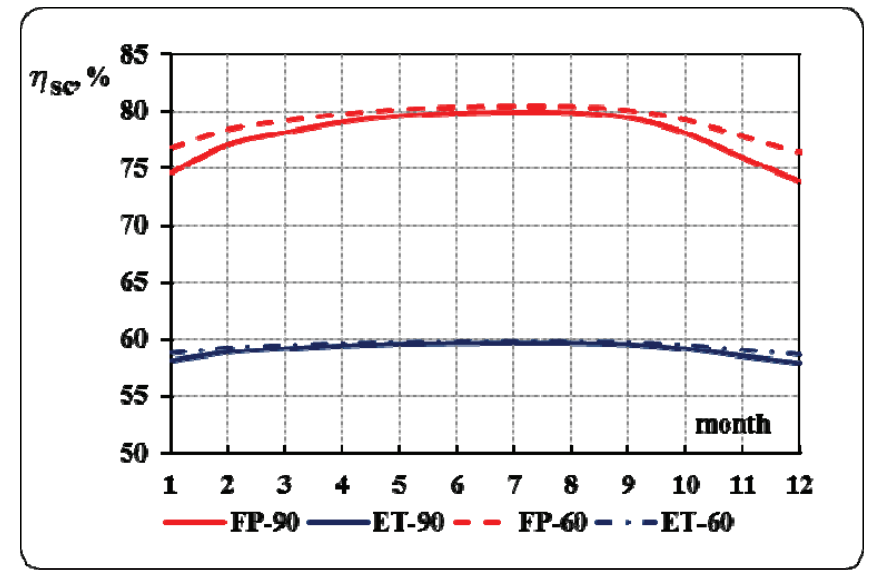

Fig. 1 Monthly efficiency of flat-plate and evacuated tube solar collectors at coolant temperatures $60^{\circ} \mathrm{C}$ and $90^{\circ} \mathrm{C}$ respectively (climatic zone 1 ) 
Along with the instantaneous efficiency $\eta_{s c}$, the critical radiation $I_{c}$ has significant impact on the energy utilized by the collectors. The monthly values at temperatures $\vartheta_{a v}=(80,70,60,50 u 40){ }^{\circ} \mathrm{C}$ and slope $\beta=0$ for the three climatic zones are shown in Fig. $2 \div$ Fig. 4 . The maximum values of $I_{c}$ are at temperature $\vartheta_{a v}=80{ }^{\circ} \mathrm{C}$ during the months with low outdoor temperatures and intensity of solar radiation, and the minimum during the summer months at $\vartheta_{a v}=40{ }^{\circ} \mathrm{C}$. For the flat-plate solar collector, the maximum values vary in the range from $362 \mathrm{~W} / \mathrm{m}^{2}$ (climatic zone 7) to $352 \mathrm{~W} / \mathrm{m}^{2}$ (climatic zone 1 ), and the minimum - from $85 \mathrm{~W} / \mathrm{m}^{2}$ (climatic zone 7) to $73 \mathrm{~W} / \mathrm{m}^{2}$ climatic zone 6 ). The corresponding values for the evacuated tube collector are significantly lower: maximum from $142 \mathrm{~W} / \mathrm{m}^{2}$ (climatic zone 7 ) to $138 \mathrm{~W} / \mathrm{m}^{2}$ (climatic zone 1) and minimum - from 33 $\mathrm{W} / \mathrm{m}^{2}$ (climatic zone 7 ) to $29 \mathrm{~W} / \mathrm{m}^{2}$ (climatic zone 1 and 6 ).

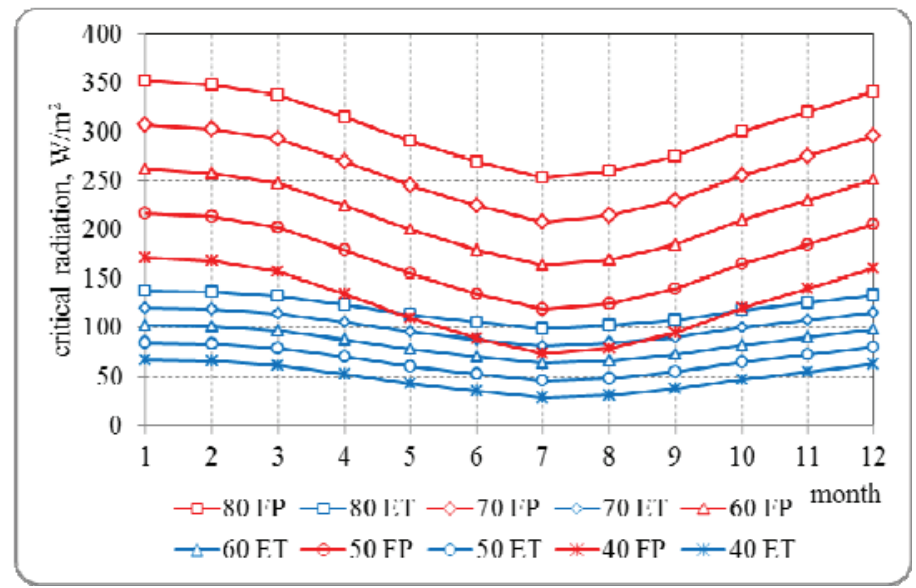

Fig. 2 Monthly critical radiation for FP and ET collectors at different temperatures of the heat transfer fluid (climatic zone 1)

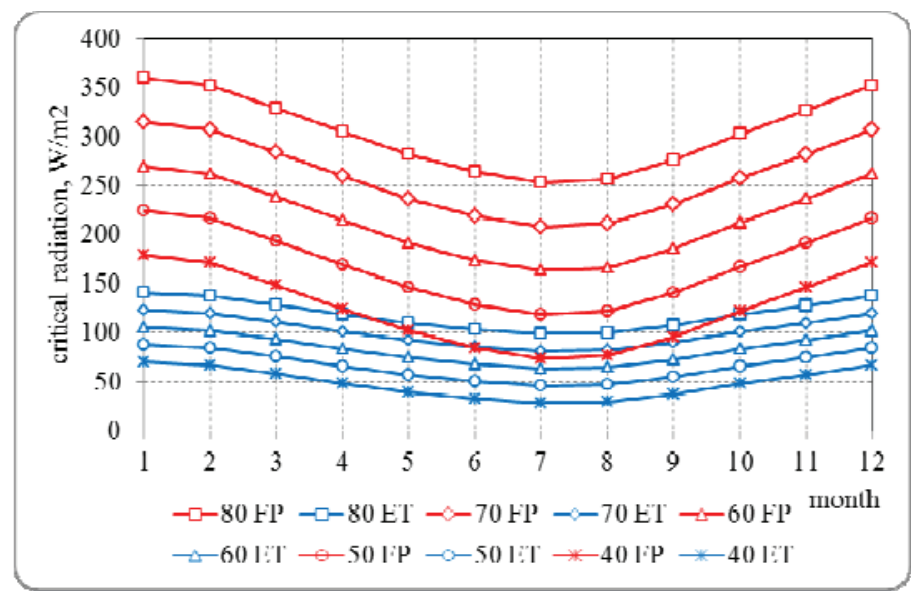

Fig. 3 Monthly critical radiation for FP and ET collectors at different temperatures of the heat transfer fluid (climatic zone 6) 


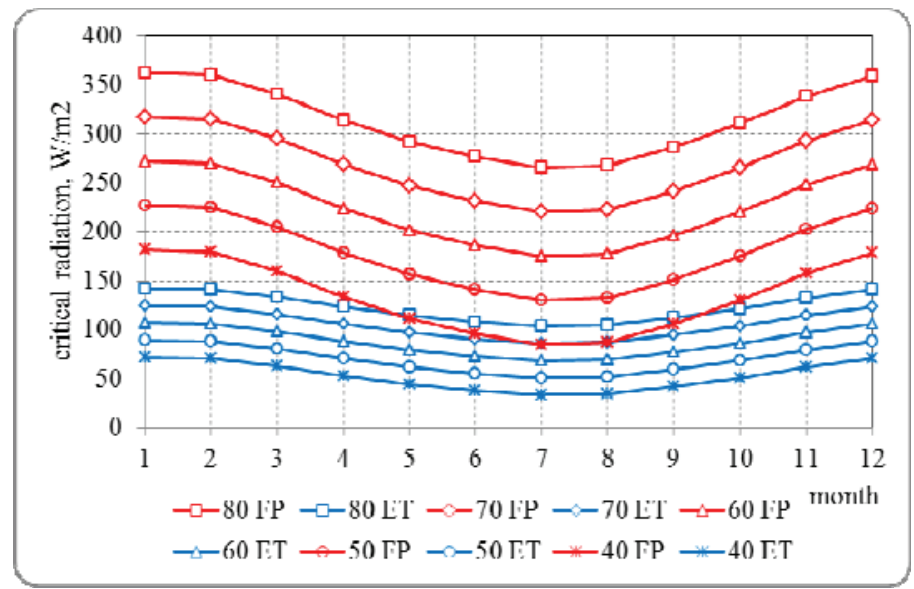

Fig. 4 Monthly critical radiation for FP and ET collectors at different temperatures of the heat transfer fluid (climatic zone 7)

The monthly values of the critical radiation determine the specific nature of the change of the utilizability factor for the two types of collectors (Fig. $5 \div$ Fig. 7). The maximum value of the daily utilizability factor $\bar{\phi}_{\max }$ for both types of collectors is found in August. During the other months, due to the lower values of the outside air temperature and the solar radiation, the daily factor $\bar{\phi}_{i}$ decreases (i - number of month). The reduction of the utilizability factor $\Delta \bar{\phi}_{i}=\left(\bar{\phi}_{\max }-\bar{\phi}_{i}\right)$ for the ET collector is significantly lower than for the FP.

The maximum values of the utilizability factor are reached at $\vartheta_{a v}=40{ }^{\circ} \mathrm{C}$. For the ET collector they vary in the range $0.93 \div 0.76$ (zone 1 ); $0.94 \div 0.79$ (zone 6); $0.92 \div 0.71$ (zone 7 ). For the FP collector the change at the same temperature is: $0,83 \div 0,49$ (zone 1 ); $0.84 \div 0.52$ (zone 6 ); $0.80 \div 0.42$ (zone 7 ).

The minimum values of the utilizability factor are found at $\vartheta_{a v}=80{ }^{\circ} \mathrm{C}$. In the case of the ET collector, they vary in the range: $0.78 \div 0.56$ (zone 1 ); $0.79 \div 0.60$ (zone 6); $0.77 \div$ 0.50 (zone 7). The minimum values of the utilizability factor for the flat-plate collector are: $0.50 \div 0.21$ (zone 1 ); $0.52 \div 0.24$ (zone 6) and $0.47 \div 0.18$ (zone 7 ).

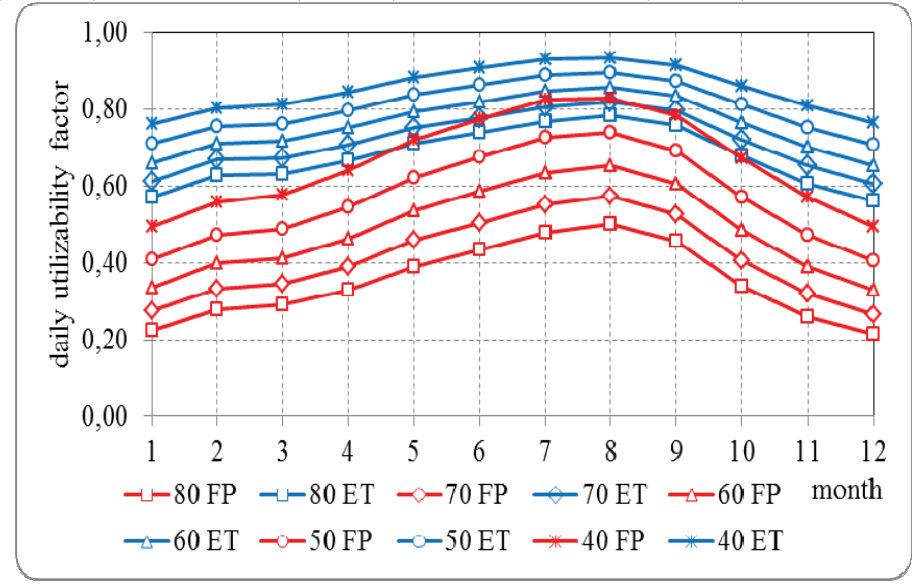

Fig. 5 Monthly value of the daily utilizability factor for FP and ET tube solar collectors at different temperatures of the heat transfer fluid (climatic zone 1) 


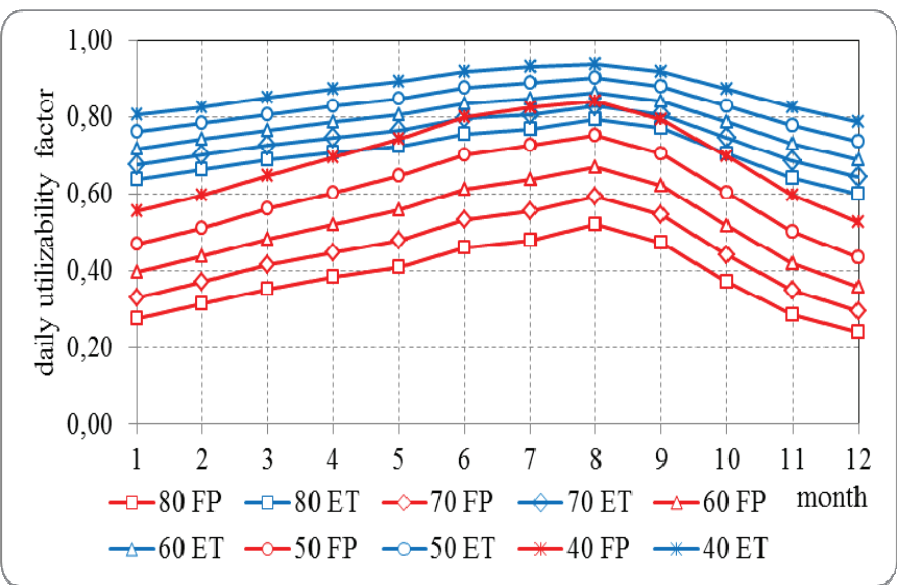

Fig. 6 Monthly value of the daily utilizability factor for FP and ET tube solar collectors at different temperatures of the heat transfer fluid (climatic zone 6)

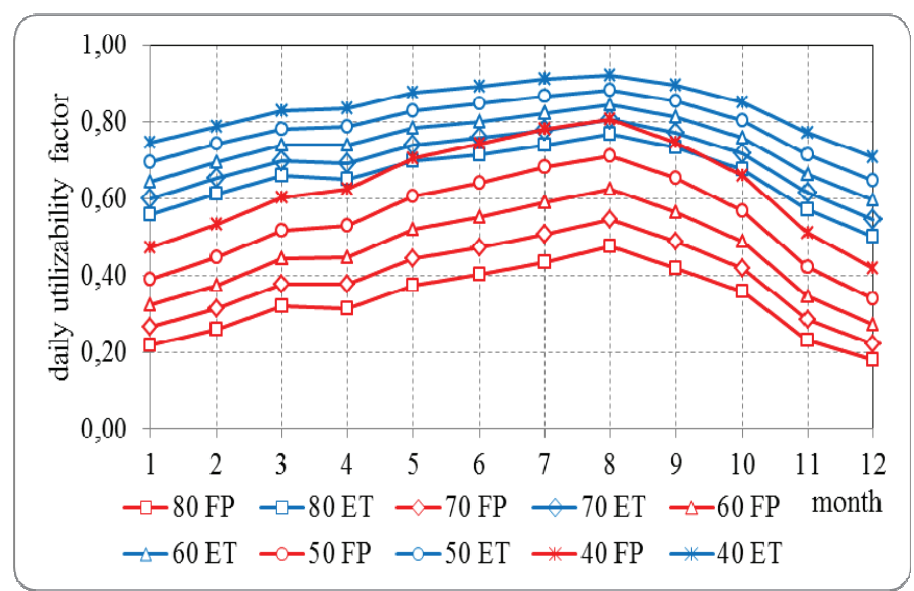

Fig. 7 Monthly value of the daily utilizability factor for FP and ET tube solar collectors at different temperatures of the heat transfer fluid (climatic zone 7)

It is obvious that the specific design of the collectors influences their optical efficiency and heat loss coefficient. The impact on the behaviour of the collectors and the degree of utilization of the solar radiation is more significant during the winter months. In this period, due to the lower value of $F_{R} U_{L}$, the advantages of the evacuated tube collectors are more pronounced. The ratio of the daily utilizability factors $\bar{\phi}_{F P} / \bar{\phi}_{E T}$ characterizing the degree of reduction of the solar radiation converted by the flat-plate collector at different coolant temperatures is shown in Figs. $8 \div$ Fig. 10 .

For the three climatic zones, at low temperature $\vartheta_{a v}=40{ }^{\circ} \mathrm{C}$ during the summer months (from June to September) the values of the ratio show a slight decrease in the range of: $11 \% \div 15 \%$ (zone 1); $10 \% \div 13 \%$ (zone 6 ); $13 \% \div 17 \%$ (zone 7 ).

As the temperature $\vartheta_{a v}$ increases, the ratio $\bar{\phi}_{F P} / \bar{\phi}_{V T}$ decreases. Its maximum values are during the summer period: $64 \% \div 59 \%$ (zone 1); $65 \% \div 61 \%$ (zone 6 ); $53 \% \div 62 \%$ (zone 7). 


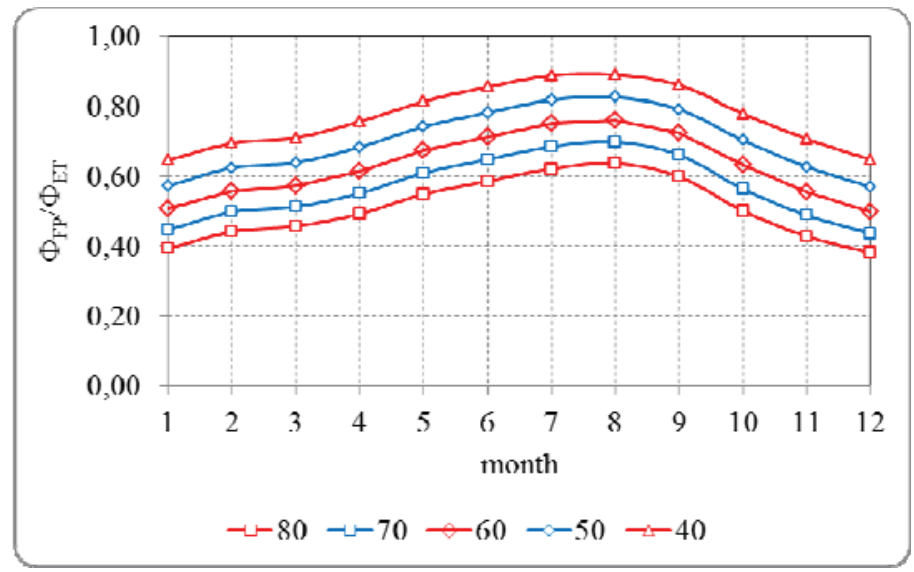

Fig. 8 Ratio of the daily utilization factors $\bar{\phi}_{F P} / \bar{\phi}_{E T}$ for flat-plate and evacuated tube solar collectors at different temperatures of the heat transfer fluid (climatic zone 1)

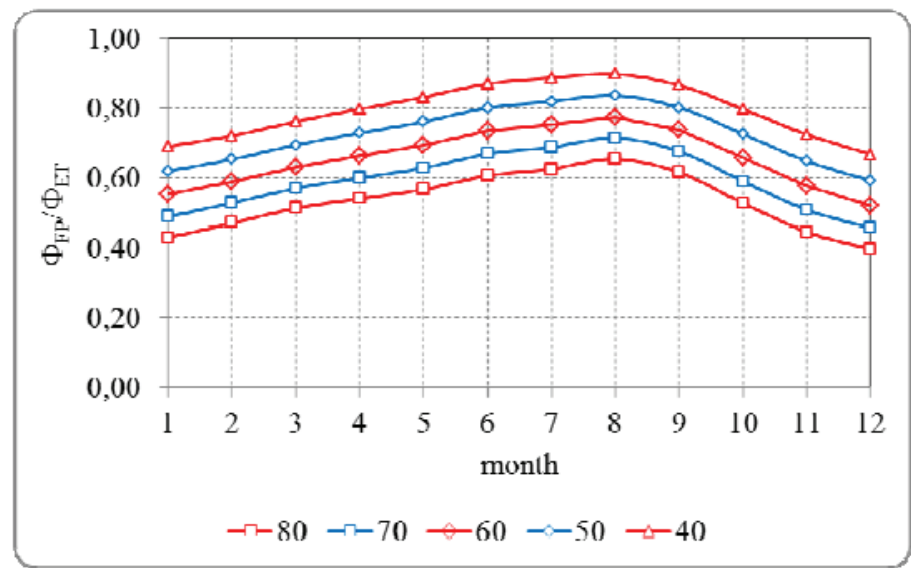

Fig. 9 Ratio of the daily utilization factor $\bar{\phi}_{F P} / \bar{\phi}_{V T}$ for flat-plate and evacuated tube solar collectors at different temperatures of the heat transfer fluid (climatic zone 6)

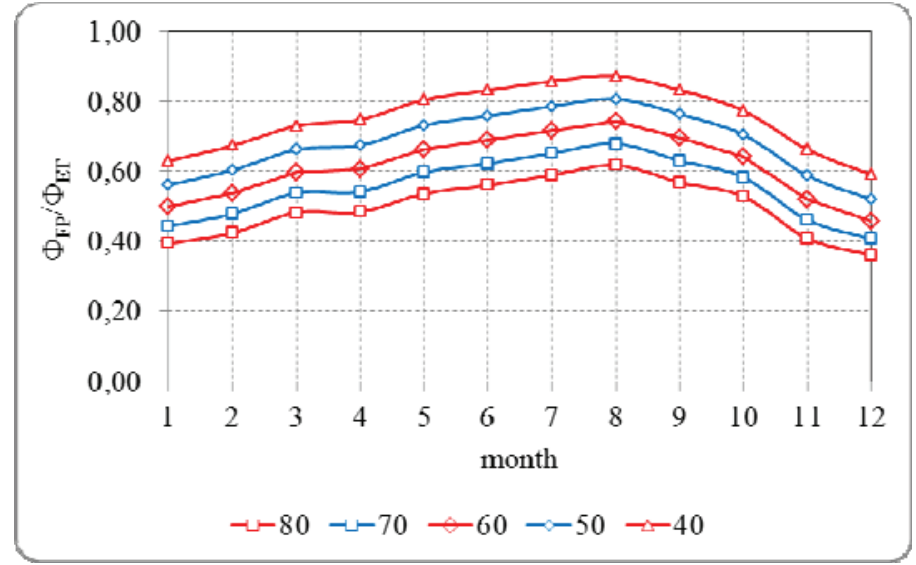

Fig. 10 Ratio of the daily utilization factor $\bar{\phi}_{F P} / \bar{\phi}_{V T}$ for flat-plate and evacuated tube solar collectors at different temperatures of the heat transfer fluid (climatic zone 7) 
The effect of the average temperature $\vartheta_{a v}$ on the solar radiation utilized by both types of collectors is shown in Fig. $11 \div$ Fig. 13. The plots are obtained for a collector tilt angle equal to the latitude. Increasing the temperature of the heat transfer fluid causes a decrease in the heat utilized by both types of collectors, but the rate of change in the flat-plat collector is higher.

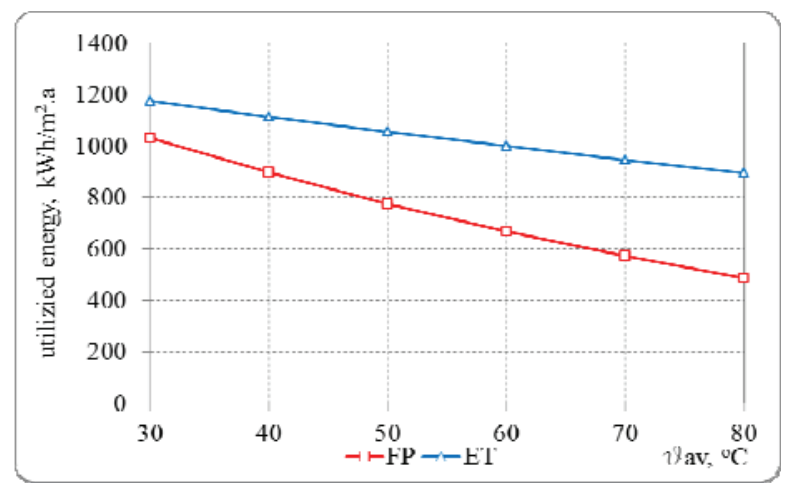

Fig. 11 Utilized energy from flat-plate and evacuated tube solar collector depending on the temperature of the heat transfer fluid (climatic zone 1)

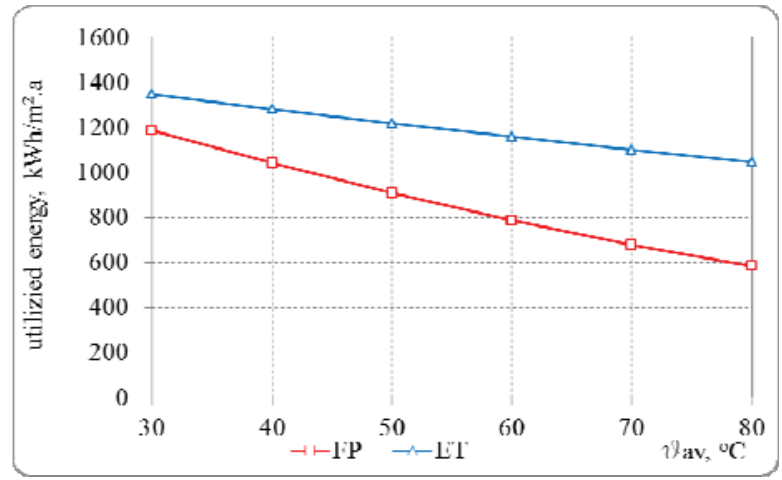

Fig. 12 Utilized energy from flat-plate and evacuated tube solar collector depending on the temperature of the heat transfer fluid (climatic zone 6)

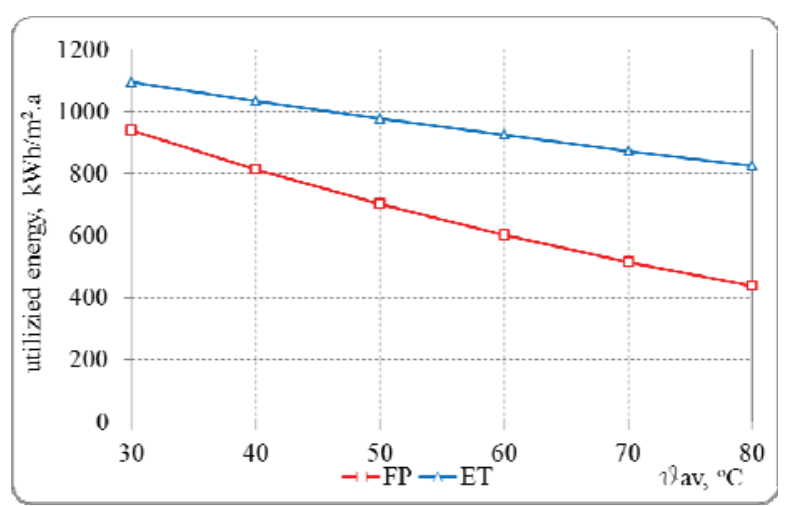

Fig. 13 Utilized energy from flat-plate and evacuated tube solar collector depending on the temperature of the heat transfer fluid (climatic zone 7) 


\section{Conclusion}

The instantaneous efficiency, determined via monthly average values for the outdoor temperature and the incident solar radiation, is higher for the flat-plate collectors than for the evacuated tube collectors. However, the long-term average performance of solar collectors also depends significantly on the critical radiation. The impact of the critical radiation can be assessed using the utilizability method.

The hourly utilizability factor, determined via monthly average climatic data, allows for a quick comparative assessment of the long-term performance of different types of solar collectors, without the use of complex calculation procedures.

Despite the lower optical efficiency, the specific design of the evacuated tube collectors and their lower critical radiation result in a greater rate of solar energy utilization at some heat transfer fluid temperatures. The impact on the behaviour of the collectors and the degree of utilization of the solar radiation is more significant during the winter months. In this period, due to the lower value of $\mathrm{F}_{\mathrm{R}} \mathrm{U}_{\mathrm{L}}$, the advantages of the evacuated tube collectors are more pronounced.

The plots obtained for the specific energy utilized at different temperatures of the heat transfer fluid can be used for initial estimation of the size of the collector array in solar thermal systems.

\section{References}

1. B. Y. H. Lui, , R. C., SE, 7, 53 (1963)

2. M. Collares-Pereira, A. Rabl, SE, 23/3, (1979)

3. D. L. Evans, T. T. Rule, B. D. Wood, SE, 28/1 (1982)

4. S. A. Klein, W. A. Beckman, JSEE, 106/393, (1984)

5. J. A. Duffie, W. Beckman, Solar Endineering of Thermal Processes. (2013)

6. N. Khartchenko.. Thermische Solaranlagen. Grundlagen, Planung und Auslegung. (1995)

7. N. Fraidenraich. O. C. Vilela, SE, 2,79 (2000)

8. S. A. Klein. SE, 21, 393 (1978) 